\title{
Educational Experiences of Blind Programmers
}

\author{
Catherine M. Baker \\ Journalism, Media \& Computing \\ Creighton University \\ Omaha, NE, USA \\ catherinebaker@creighton.edu
}

\author{
Cynthia L. Bennett \\ Human Centered Design \& Engineering \\ University of Washington \\ Seattle, WA, USA \\ bennec3@uw.edu
}

\author{
Richard E. Ladner \\ Computer Science \& Engineering \\ University of Washington \\ Seattle, WA, USA \\ ladner@cs.washington.edu
}

\begin{abstract}
As diversity efforts in computer science begin to recognize disabled programmers as an underrepresented group, we step back to chronicle the experiences of blind programmers in higher education. Through a survey and follow-up interviews with 10 blind programmers, we share reflections and barriers important for the computing education community to understand as we attempt to welcoming cultures for disabled programmers. Our findings illuminated a variety of barriers blind programmers faced in college and the impact that they had on their ability to succeed in the field. We found that barriers permeate all parts of these blind student's' education from accessing the materials and doing the homework to working with professors. These barriers increased feelings of the isolation, decreased motivation especially when tasks were inaccessible, and prevented them from learning all the concepts covered in their degree program.
\end{abstract}

\section{CCS CONCEPTS}

- Human-centered computing $\rightarrow$ Accessibility $\rightarrow$ Empirical studies in accessibility

\section{KEYWORDS}

Computer science; education; blind programmers; accessibility

\section{ACM Reference format:}

Catherine M. Baker, Cynthia L. Bennett, Richard E. Ladner. 2019. Educational Experiences of Blind Programmers. In Proceedings of $50^{\text {th }}$ ACM Technical Symposium on Computer Science Education (SIGCSE '19), February 27-Mar. 2, 2019, Minneapolis, MN, USA. ACM, NY, NY, USA, 7 pages . DOI: https://doi.org/10.1145/3287324.3287410

\section{Introduction}

Diverse teams benefit companies, however computer science is not a very diverse field [8]. In reaction, several diversity efforts have sprung up to raise participation. While necessary, most have focused on increasing the participation of women and

Permission to make digital or hard copies of all or part of this work for personal or classroom use is granted without fee provided that copies are not made or distributed for profit or commercial advantage and that copies bear this notice and the full citation on the first page. Copyrights for components of this work owned by others than the author(s) must be honored. Abstracting with credit is permitted. To copy otherwise, or republish, to post on servers or to redistribute to lists, requires prior specific permission and/or a fee. Request permissions from Permissions@acm.org. SIGCSE '19, February 27-March 2, 2019, Minneapolis, MN, USA

(C)2019 Copyright is held by the owner/author(s). Publication rights licensed to ACM. ACM 978-1-4503-5890-3/19/02 ..\$15.00

https://doi.org/10.1145/3287324.3287410 minorities, but few have considered disability. Notably, AccessComputing [19] has attempted to increase the participation of people with disabilities in computer science by cultivating mentorships with students and professionals with disabilities, and financially supporting conference attendance and internships. But AccessComputing does not penetrate dayto-day classroom environments. In order to widen diversity efforts to support computer science professionals with disabilities, it is important to understand the challenges they must overcome. Our work focuses on a subset of this concern, challenges faced by blind students during postsecondary computer science coursework.

As much of the academic literature thus far has focused on either introduction to computer science $[3,9,17]$ or the experiences of these engineers once in the industry [11], we focus our research on the period between the two, computer science degree acquisition. We know that students with disabilities are less likely to study STEM fields and more likely to drop out of STEM programs than their non-disabled peers [5]. Based on this, we would like to understand the barriers that blind students face in computer science in hopes of increasing the number that persist in their degree. Some preliminary work suggests some of these challenges. Mealin and Murphy-Hill [2] found that many blind software engineers were not using many of the tools built in to integrated development environments (IDEs) and hypothesized it was due to the students not learning them in school. Additionally, in a blog post [6], Doustdar mentioned he chose to continue his education outside of a university as his computer science coursework was highly visual. We wish to discover a more nuanced and comprehensive view of the challenges these students face during their studies.

\section{Related Work}

While little research chronicles the experiences of blind programmers while acquiring their degree, some work has focused on the curricular changes and accommodations made by instructors of blind students $[6,8]$. But this work lacks student perspective. The afore-mentioned interview study by Mealin and Murphy-Hill [11] comprises the only glimpse of educational experiences by blind computer science professionals with the aim to raise awareness to computing researchers. While this work introduces how blind programmers navigate code, became interested in computer science and navigated misperceptions about their disability in professional settings, our study follows this to elucidate more specific challenges encountered across the 
entire computer science degree requirements and social experiences with professors and peers.

The accessibility challenges with IDEs and code editors have been studied and a few have been designed with a blind developer in mind. Some have focused on making specific existing environments more accessible. Emacspeak [13] is a spoken interface for Emacs. Sodbeans [17], which is built into NetBeans, and EdSharp [20] augment the information that is provided by the screen reader. Other tools increase access to individual aspects of coding, including IDE enhancements. Potluri et al. [12] started by categorizing the accessibility issues in IDEs and then created CodeTalk, a Visual Studio plugin, to address a subset of the issues discussed. Baker et al [1] created StructJumper, an Eclipse plug-in to help blind students navigate in the code. Smith et al. [15] created a plug-in to make the program hierarchy more accessible. Stefik et al. [16] used audio cues to highlight a change in scope as a program executed. Vickers et al. [18]'s system plays audio cues upon entry and exit of program structures. Finally, Balik et al. [2] created GSK, a tool to help blind students create and share graphs crucial for participating in many computer science classes. These tools importantly remove barriers to inaccessible aspects of computer science. Our study steps back to quantify these barriers in hopes of better understanding how they impact learning.

Finally, introducing blind students to computer science has gained recent attention since many beginner coding tutorials remain inaccessible. Stefik et al. [17] created an educational infrastructure with accessible programming activities and a supplementary curriculum for teachers. Others introduce programming concepts with robotics [10], Twitter data [9], chat bots [3] and audio output [14] to enhance nonvisual interactivity. These approaches aim to recruit blind students in to computer science. In this study, we instead focus on barriers encountered after our participants decided to pursue a career in computing.

\section{Methods}

\subsection{Survey and Interviews}

We conducted a survey and follow-up semi-structured interviews. The survey was conducted to gain a broad overview of the problems blind programmers encountered during their degree. The interview questions were gleaned from survey results as we hoped to gain a deeper understanding of participants' responses and experiences. The interviews took 3060 minutes and were transcribed for open coding and analysis afterwards.

\subsection{Participants}

Survey participants were recruited using mailing lists, research contacts and snowball sampling. On the survey, participants were asked if they would be willing to participate in the follow up interview. Inclusion criteria for study participation were that they completed a degree in computer science or a related field, they used a screen reader while completing the degree, and be 18 or older. After closing the survey, we removed responses that were likely spam (i.e. had multiple responses that did not make sense for the question) and concluded with 15 responses to the survey. All 15 survey respondents were male with an average age of 31.7 (SD = 6.9). Six participants had a graduate degree. Ten participants did their degree in North America, the other five in Europe. The median graduation year was 2009 (range 1995-2014). Participants averaged 12 years of computer science experience $(\mathrm{SD}=7.5)$.

We conducted the interviews with 10 of the survey respondents (referred to as i1-i10). Interviewees were selected to represent a range of experiences including reported barriers, when they attended school, and whether they completed a graduate degree. The average age of the interview participants was 29.2 (S.D. = 5.1). Four of the participants had received a graduate degree. Six of the participants did their degree in North America, the other four in Europe. The median graduation year was 2009.5 (range 1995-2014). Participants had an average of 12.3 years of computer science experience (S.D. $=7.8$ ).

\subsection{Analysis}

Interviews were audio recorded and transcribed. After reviewing all of the transcripts, the authors used open coding with two researchers initially coding together to establish the code book. Once the code book was established, the authors coded the remaining interviews independently. Once all interviews were coded, the researchers reviewed the interviews coded by the other, added any codes that were missed, and arbitrated any disagreement regarding the application of codes.

\section{Results}

Survey and interview results revealed a variety of issues that students face while completing their degree. These barriers came in the form of inaccessible materials and assignments, and from faculty misperceptions about capabilities of blind programmers. In the survey, 8 of the 15 respondents reported at least half their classes had inaccessible portions. In the following sections, we will describe these challenges in detail.

\subsection{Technology}

This section details the current state of IDEs and other technologies commonly used by our participants. On the survey, participants were asked to detail their preferred set-up(s) for coding. The four most common IDEs were Visual Studio (7 participants), Eclipse (6 participants), Notepad (3 participants), and Notepad++ (3 participants). Though IDEs and editors designed with blind programmers in mind have been created ([20], [13], [17]) only 4 participants indicated they used one of these IDEs. Eleven participants indicated which screen reader they use most often. JAWS was the most common screen reader listed (8 participants), followed by NVDA (3 participants), Window Eyes (2 participants), and Voiceover (2 participants). Finally, 5 participants used a Braille display, while 3 did not. The 
other 7 participants did not indicate explicitly whether or not they used a Braille display.

We found that many participants encountered issues with IDEs. The accessibility challenges ranged from completely unusable to advanced features proving inaccessible. All but three respondents to the survey had accessibility challenges with the IDEs that they used most often. Common problems indicated on the survey were interface builders (6 participants), debuggers ( 3 participants), syntax highlighting (2 participants), and diagrams (2 participants).

Additionally, participants clarified that while an IDE may be accessible, learning to use it was much more complex. Most guides for IDEs that participants attempted to use were geared toward sighted users, often littered with directions like "click here" which made them irrelevant to a blind programmer. Determining keyboard equivalents was complex, often leading participants away from assignments in search alternatives. Unsurprisingly, we learned that participants like i9 with prior knowledge of the IDEs found it essential for setting them up to succeed.

Attempting to, and failing to, use inaccessible IDEs deterred some participants from trying new ones. One participant said:

And like my confidence was pretty low that these programs would even work if I had the time to spend. So I was kind of going under this assumption that they wouldn't anyway. And I think I would have been right in most cases, but I don't know. ... So I didn't have time to spend and you know, put like 40 hours into Eclipse and then learn, oh ok cool, you know, it's not accessible. - i1

The burden of spending so much extra time to no avail stuck with i1 to the point that potentially wrongfully assuming an IDE would be inaccessible was a more efficient use of his time.

For some of our participants like i8, choosing to avoid learning new IDEs during university was a purposeful choice that, in the short term, mitigated some of the overhead skill acquisition in order to keep up with his classes. However, such choices came with tradeoffs. I8 is now learning how to use a debugger as he never used one in college. He learned that his previous strategies were ineffective in comparison.

Another barrier came when participants were asked to complete assignments with unique software downloaded onto specific machines. Often, this software was built for beginner students meant to direct their attention from IT to learning programming concepts. But these computers remained restrictive disallowing some of our participants from downloading important assistive technologies onto them.:

But the problem was that you could only access that server from the lab machines and the lab machines didn't have any speech on them. So I couldn't use it all. So I actually - I ended up having to set up my own machine and you know set-up Oracle, set up PHP, Apache, and all things like that. But I had to get the assignment in, you know, to the same deadline that everyone else did. - i6
Participants were burdened when they had to configure separate machinery. This often required extra work which distracted them from coursework. Additionally, lab spaces serve additional purposes other than just access to the technology. Lab spaces can serve as a communal space for students and without access to the machines in these spaces may be less inviting to blind students.

\subsection{Accommodations}

One of the factors that affected a student's experience was the quality of the accommodations that were provided. In this section, we will discuss their experiences related to these accommodations in regard to accessing lectures, materials, and assignments.

4.2.1 Lecture. One of the major problems blind students face in lecture is missing context, as what is spoken does not replicates visual content:

The professor would say something like 'sizeof int,' right? So he would leave out that it was actually 'sizeof left parenthesis int right parenthesis semi-colon. ...' So you miss all that. So when I first started learning $C$ in college, I would actually write 'sizeof space int semi-colon' on my exams. $-i 2$

Issues such as this were compounded when the lecturer handwrote and gestured to content rather than speaking it out. I2 acknowledged that requesting content be read out loud presented a new experience for the lecturer and would sit at the front of the room as a physical reminder of the accommodation. When the professor did not verbalize their handwriting and did not provide the same information in accessible course materials, participants relied on friends in the class whose notes were likely also inaccessible; for i1, this meant receiving unreadable notes in MathType or Microsoft Word's Equation Editor.

4.2.2 Materials. Our participants had difficulty obtaining course materials such as textbooks and handouts in an accessible format on time. Participants tended to prefer one of a few different mediums: Braille, audio, or electronic but each format had its pros and cons.

Producing Braille textbooks is time consuming, requires specialized equipment and expertise, and is expensive to create. Those who received Braille textbooks cited large delays interfering with their learning. I2 ordered braille transcription 2 months in advance to receive them when classes started. I1 would sometimes not get the braille book until over half way through the term, if at all. In order to have access to the book for the entire term, he would sometimes drop and retake a course. To mitigate the cost and time factors, i4 ordered books from a Braille library. However, they often were not the same book assigned, but the faculty would look them over and determine if they adequately covered the topics.

Multiple (i2, i4, i7, i8) participants used audiobooks from sites like Learning Ally [21]. Books from Learning Ally were appreciated because they recruited readers versed in the subject. 
This had two benefits. The first was that they could read the subject material in a way that made sense. For things like code, they would know what needed to be read, such as punctuation. Additionally, they would often describe the diagrams by prioritizing the pertinent information. But they also had a downside. One participant found the spoken code very hard to listen too:

So, books and audio when it comes to programming is very inefficient. Some of the readers, what they would do, is they would actually spell the entire code. So they would say $f-u-n-c-t-i-o-n$. Space... - i2

Since there is no established standard for verbalizing code, audio book readers sometimes omitted information. For example, participants indicated readers would fail to communicate indentations which can be consequential for certain programming language. Additionally, it is not possible to search audiobooks, which can make them less useful for looking up information.

Participants loved obtaining an electronic format of the textbook as they were versatile and searchable. For example, participants could read content with a screen reader or refreshable braille display, and write notes and highlight important content. However, electronic formats were difficult to obtain. Three of the interview participants (i1, i5, i6) contacted the textbook publishers directly to obtain a premade electronic version, but only one actually received a textbook. Those unable to get the electronic version directly from the publisher scanned the hardcopy book and used Optical Character Recognition (OCR) software to extract text. However, OCR works best with prose and stem-related content including computer code is often interpreted incorrectly. Since correct syntax is imperative in computer science, even intermittent errors could confuse students as to whether they did not understand the material or whether their OCR version of the textbook was inaccurate. One participant's office providing accommodations for students with disabilities hired workers with knowledge of computer science and were therefore able to correct OCR-produced errors. However, if the student was unable to get the OCR corrected, explicitly mentioned by (i3, i5, i6), then they received the textbook with the afore-mentioned errors. One participant described the effect as:

Then scan was always the last scenario because that would have a drastic effect on my mark. You know, to the point where I was ... getting First [highest grade] for the things where I had electronic copies of books readily available to me, but I was barely passing modules where I had to get the book scanned. - i6

Textbook formats varied but all had pros and cons. Students experimented with different types but never completely succeeded in obtaining their course materials on time in an accessible format.

Another common resource students needed access to were diagrams. In general, they were either provided in a tactile form or a verbal/textual description. Sometimes students would only get a small subset of the diagrams made accessible because conversion took time, special equipment in the case of tactile graphics, and expertise. Additionally, the source of descriptions varied. For one student, the professor included descriptions on his slides. Others relied on friends or family members to describe the images. We discovered that who provided the descriptions largely impacted their accuracy. Our participants reiterated that diagram describers need to be knowledgeable of the material:

And it's kind of like well, ok, I need to know where the
switches are and stuff like that. ... But, you know, if you
don't know about computers, you can't just look at some of
these diagrams and give an accurate description of them. -
i6

Participants encountered similar miscommunication when someone served as their go-between during exams. A common scenario consisted of a reader describing questions on the exam and transcribing answers as participants dictated. Multiple participants lamented these experiences negatively. i4 described one of his tests:

And the problem was the person they got to actually do the writing for me was a chemistry post graduate - had never done this part of mathematics before. So he didn't know what the hell he was writing. - i4

Timely and accessible textbooks and diagrams proved important but rarely-available components to participant success. It was important that description authors were aware of the field Second, since participants were still learning the content, they were unqualified to provide the reader instructions on what and how to communicate. However, services like Learning Ally which recruited subject matter experts to read computer science textbooks did not mitigate this barrier given the limits of audio books on searching and inconsistent descriptions given no universal reading standard. Finally, exams represented negative experiences for our participants when nonexperts not only could not describe content but when they could not transcribe answers as intended.

4.2.3 Assignments. Some participants were provided alternate assignments or exemptions during their computer science degree programs. These examples spanned using different technologies to complete coursework, building a different system, leveraging human assistance, receiving grades based on the accessible components, and being excused altogether.

One of the most common issues occurred when assignments steered students toward an inaccessible IDE. This was often not consequential as assignment requirements could be fulfilled regardless of the IDE, but it did mean that they undertook extra work to learn the IDE on their own and they may not have had access to the same tools (i.e. debugging).

Another common alteration was changing the form factor of the assignment, resulting in different output with similar application of programming concepts. Participants sometimes wrote text descriptions of non-textual answers (i5 and i9) or doing a console based application instead of GUI application (i3, i6, i10). 
However, other participant scenarios exemplified two very different assignments. I9 built a chat application once when the rest of his class built a visual game. This application "covered some common concepts and others which the game did not. So it was equal but not the same."

The second major assignment change occurred when the participant was assigned a sighted partner to relay visual information, or when a reader completed visual aspects under the participant's direction. I6 was asked to create a drawing application. He had a sighted peer help him by watching him run his code to communicate if it succeeded, but he wasn't very motivated by the assignment:

\section{And to be completely honest, I didn't put a huge amount of effort into that assignment. Because I just hated the idea of kind of spending hours and hours of making something I'd just never be able to use. $-i 6$}

The student's motivation was decreased by having an assignment that he did not find exciting as he would be unable to actually use (and debug) the output. The low effort meant that he later realized that he did not know those topics as well, which is a challenge when topics build upon those earlier topics they did not learn well.

Some professors did not adapt assignments but ambiguously communicated they would consider the extra challenges when grading. I2, described just one of a few similar experiences:

He said, you know, as long as your code is written to the best of your ability. ... So he said double check the logic and stuff and you know, we will realize that you were never actually able to compile and run this program. $-i 2$

I2 was okay with this outcome as he felt confident about the content. However, it likely is not a good option in general. The process of understanding errors and figuring out how to fix them was part of the assignment that he was not able to do and thus he may not have learned as much as if he had been able to read the output and properly debug errors.

Finally, although rare, some participants were excused from individual assignments, portions of courses, and courses altogether. Participants cited professor disbelief in a blind student. For I6, this meant he was talked out of taking an elective. Most exempt courses consisted primarily of graphical or electronics content. Participants had to advocate strongly to enroll when the professor or department would have waived the requirement. I1 took an independent study version of a course in lieu of the established version which was inaccessible, but his attempts to adapt course content with the instructor were unsuccessful, defeating the purpose of the specialized course opportunity. Several participants relayed faculty were forthcoming about not knowing how to teach them, imagining exemption from visuallybased content and assignments over constructing accessible alternatives. Common in these stories is that participants were not interested in missing out on any assignments or courses. Instead, they had to assert their right to complete all degree requirements.
Adapted or removed assignments altogether carried repercussions. Differences in assignments could be ambiguous as to whether they were scaffolding a similar learning experience or whether they would be evaluated objectively. Participants further had to rely on peers or readers, decreasing their engagement with the content. Finally, inaccessible assignments increased workload and interfere with concept mastery, deficiencies that some participants did not realize for years.

\subsection{Social Impacts}

We found in our interviews that social factors also impacted participant experiences. I4 summarized social support as paramount:

You need both individual buy-in and you also need organizational buy-in from the university. Otherwise you can actually have the best and brightest student in the class who happens to be blind and if they can't get the requisite support, then they've got a huge, huge, huge problem. - i4

As such, we briefly overview the impact of faculty and other students on participants' educational experience.

Faculty were often responsible for accommodating students directly, most commonly by sending course materials even when they did not typically distribute them to motivate class attendance. Participants reported incidents when faculty would refuse to send these materials and i4 had to enroll the assistance of university compliance personnel when advocating for himself did not work. When faculty were unwilling to work with the students, it made it difficult for students. Five participants (i1, i2, i3, i4, i5) mentioned having push back from the faculty or dropping courses to have a more accommodating faculty member. In particular, i2 had faculty that encouraged him to change his major and he nearly dropped his degree because he was frustrated with having to fight to gain access to materials. However, participants also praised supportive faculty; i1 remembered one faculty member who sent slides before each lecture, complete with text descriptions of diagrams.

Accessibility barriers also manifested during group projects. Several projects required students submit diagrams of how the software will work. I6 recounted his team leaving him out since he couldn't discern diagram drawings based on conversation alone

But even so, it wasn't ideal. I mean they were understanding, but, you know, there were lots of sessions where they'd all be talking and I wouldn't be able to say anything at all. Not because I didn't want to, but just because I couldn't really follow what they were talking about. - i6

Participants had difficulty following real-time creation of inaccessible materials to be submitted for their group projects. This had further consequences than just their participation in the work the group was doing. I6 continued, "But it's also a social thing, you know. Cause if you're the one person in the group that doesn't talk, you know, guess who the one person who doesn't get 
invited for drinks afterwards is."Being unable to participate in parts of the group projects was isolating for some participants. As other students can be help one another study and navigate computer science altogether, participants who did not contribute equally during group projects experienced isolation.

\section{Discussion}

We uncovered numerous barriers that characterize computer science education for blind students. Our participants recalled exploring numerous alternative technologies, textbooks, and assignment formats which added extra work. Further, accessibility barriers fostered disbelief that new technologies would be accessible, decreasing motivation to engage with important tools and concepts they would later need in their careers. Finally, social factors were hugely important but under addressed. We'll now highlight three areas for collaboration among educators and researchers toward removing these barriers.

\subsection{Enforce Accessible Course Materials}

First, we believe that enforcing the use of accessible course materials will alleviate pressure for blind students to explore accessible alternatives. Throughout our interviews, it was clear accommodations often remediated tools that could have been designed more accessibly. To enforce use of high quality accessible materials and tools, it will require partnerships with faculty, curriculum developers, education technology researchers and companies, university IT, and offices for students with disabilities. Faculty will need to be involved to provide subject matter expertise, university personal who prepare and implement accommodations for students with disabilities will provide more expertise on specific issues faced by students with disabilities and the creation of the alternative materials. Additionally, if curriculum developers and educational technology research consider the needs of students with disabilities from the beginning, then it can decrease the need for accommodations.

Further research is needed to improve the process of creating accessible materials. Currently, the central challenges include time, expertise, and specialized equipment needed to provide accessible alternatives. This not only burdens students but requires faculty to have their materials ready far in advance. Alternative materials production then rests on the few experts, removing agency from blind students and faculty until accessible materials are sent back in return. There has been some work starting in this area to help improve the process of creating tactile formats of the images in a textbook using the Tactile Graphics Assistant [7]. However, this is just one piece and we need to continue improving alternative materials production to be expedient and producible by nonexperts. This work can uplift everyone involved in providing accommodations by allowing students and faculty to be able to play a more active role.

\subsection{Support Faculty Learning}

Second, we found that faculty need more support. Blind participants were largely the only information source for faculty.
Yet blind students are not experts in accessible education, and when left to retool inaccessible curriculum, faculty can be further burdened or even suggest damaging alternatives like exempting assignments. AccessComputing [4] aims to equip instructors with Universal Design for Learning techniques such that students with disabilities can engage with few accommodations. Faculty and disability service professionals can also participate in communities of practice to create networks that can help identify steps to make classrooms and programs more accessible and inclusive and recruit more students with disabilities [22]. Researchers must consider how to scale these trainings and approach departments and universities for greater buy-in so faculty participation is expected and rewarded.

\subsection{Foster Social Integration of Blind Students}

Finally, blind students should be intentionally socially integrated. Accommodations to functionally be able to complete assignments are viewed as the means for disabled students to access their education. Yet we found these modifications were insufficient and could even increase isolation when, for example, an alternative assignment meant a participant was the only person working with a partner or building a different system altogether. First, blind students should have access to the spaces, machinery, and events hosted by departments. Recruitment events to improve diversity should explicitly include disability as an underrepresented group. Finally, adapted coursework should minimize social isolation and assignments deemed too visual for blind students should be replaced for the entire class with more inclusive alternatives.

Further research on creating more accessible technologies, such as collaborative accessible graph creation, could increase engagement from blind students during group work and other assignments. As technologies become more accessible, there will be less burden on students to find good accommodations.

\section{Conclusion}

This study shows that blind students encounter numerous barriers to obtain a computer science degree, and current research and efforts are only scratching the surface. Existing programs must be amplified and supplemented with more direct support from educational technology researchers and universities to remove barriers. In this paper, we revealed specific obstacles blind students faced and posited three overlapping areas for collaboration among educators and researchers to foster more fair and welcoming programs. By implementing accessible course materials and tools, supporting faculty accessibility education, and prioritizing integrating blind students, we hope to provide some steps forward toward a more diverse computing field.

\section{ACKNOWLEDGMENTS}

This material is based upon work supported by the National Science Foundation Graduate Research Fellowship Program under Grant No. (DGE-1256082). 


\section{REFERENCES}

[1] Catherine M. Baker, Lauren R. Milne, and Richard E. Ladner. 2015 StructJumper: A Tool to Help Blind Programmers Navigate and Understand the Structure of Code. In Proceedings of the 33rd Annual ACM Conference on Human Factors in Computing Systems - CHI '15, 3043-3052. https://doi.org/10.1145/2702123.2702589

[2] Suzanne P. Balik, Sean P. Mealin, Matthias F. Stallmann, Robert D. Rodman, Michelle L. Glatz, and Veronica J. Sigler. 2014. Including Blind People in Computing Through Access to Graphs. In Proceedings of the 16th International ACM SIGACCESS Conference on Computers \& Accessibility ASSETS '14, 91-98. https://doi.org/10.1145/2661334.2661364

[3] Jeffrey P. Bigham, Maxwell B. Aller, Jeremy T. Brudvik, Jessica O. Leung, Lindsay A. Yazzolino, and Richard E. Ladner. 2008. Inspiring Blind High School Students to Pursue Computer Science with Instant Messaging Chatbots. In Proceedings of the 39th SIGCSE Technical Symposium on $\begin{array}{llll}\text { Computer Science Education - SIGCSE '08, } 449 . & \text {. }\end{array}$ https://doi.org/10.1145/1352322.1352287

[4] Sheryl Burgstahler. 2008. Equal access: \{Universal\} design of instruction. $\begin{array}{llll}\text { Retrieved November } & 13, & 2018 & \text { from }\end{array}$ https://www.washington.edu/accesscomputing/sites/default/files/doitsync/files/Equal-Access-Universal-Design-of-Instruction.pdf

[5] Sheryl Burgstahler and Richard Ladner. 2006. AccessComputing: From Research to Practice | The Alliance for Access to Computing Careers. $\begin{array}{llll}\text { Retrieved } & \text { May } & 3, & \text { from }\end{array}$ http://www.washington.edu/accesscomputing/resources/accesscomputingresearch-practice

[6] Parham Doustdar. 2016. The Tools of a Blind Programmer - Parham Doustdar's Blog. Retrieved April 21, 2016 from https://www.parhamdoustdar.com/2016/04/03/tools-of-blind-programmer/

[7] Chandrika Jayant, Matt Renzelmann, Dana Wen, Satria Krisnandi, Richard Ladner, and Dan Comden. 2007. Automated Tactile Graphics Translation: In the Field. Proceedings of the 9th International ACM SIGACCESS Conference on Computers and Accessibility - Assets '07: 75. https://doi.org/10.1145/1296843.1296858

[8] Maggie Johnson. 2015. The Computer Science Pipeline and Diversity: Part 1 - How did we get here? Retrieved May 7, 2016 from http://googleresearch.blogspot.com/2015/07/the-computer-science-pipelineand.html

[9] Shaun K. Kane and Jeffrey P. Bigham. 2014. Tracking @stemxcomet: Teaching Programming to Blind Students via 3D Printing, Crisis Management, and Twitter. In Proceedings of the 45th ACM Technical Symposium on Computer Science Education - SIGCSE '14, 247-252. https://doi.org/10.1145/2538862.2538975
[10] Stephanie Ludi. 2013. Robotics Programming Tools for Blind Students. In 28th Annual International Technology and Persons with Disabilities Conference Scientific/Research Proceedings. Retrieved May 26, 2016 from http://scholarworks.calstate.edu/handle/10211.3/121968

[11] Sean Mealin and E Murphy-Hill. 2012. An Exploratory Study of Blind Software Developers. In Proceedings of 2012 IEEE Symposium on Visual Languages and Human-Centric Computing - VL/HCC '12. Retrieved February 27, 2014 from http://ieeexplore.ieee.org/xpls/abs_all.jsp?arnumber $=6344485$

[12] Venkatesh Potluri, Priyan Vaithilingam, Suresh Iyengar, Y. Vidya, Manoha Swaminathan, and Gopal Srinivasa. 2018. CodeTalk. In Proceedings of the 2018 CHI Conference on Human Factors in Computing Systems - CHI '18, 111. https://doi.org/10.1145/3173574.3174192

[13] T. V. Raman. 1996. Emacspeak---Direct Speech Access. In Proceedings of the Second Annual ACM Conference on Assistive Technologies - Assets '96, 32-36. https://doi.org/10.1145/228347.228354

[14] Jaime Sánchez and Fernando Aguayo. 2005. Blind Learners Programming Through Audio. Extended Abstracts on Human Factors in Computing Systems - CHI '05: 1769-1772. Retrieved February 27, 2014 from http://dl.acm.org/citation.cfm?id=1057018

[15] Ann C. Smith, Joan M. Francioni, Mohd Anwar, Justin S. Cook, Asif Hossain, and M. Fayezur Rahman. 2003. Nonvisual Tool for Navigating Hierarchical Structures. In Proceedings of the 6th International ACM SIGACCESS Conference on Computers and Accessibility - ASSETS '04, 133. https://doi.org/10.1145/1029014.1028654

[16] Andreas Stefik, Christopher Hundhausen, and Robert Patterson. 2011. An empirical investigation into the design of auditory cues to enhance computer program comprehension. International fournal of HumanComputer Studies 69, 12: 820-838. https://doi.org/10.1016/j.ijhcs.2011.07.002

[17] Andreas M. Stefik, Christopher Hundhausen, and Derrick Smith. 2011. On the Design of an Educational Infrastructure for the Blind and Visually Impaired in Computer Science. In Proceedings of the 42nd ACM Technical Symposium on Computer Science Education - SIGCSE '11, 571. https://doi.org/10.1145/1953163.1953323

[18] Paul Vickers and James L Alty. 2002. When bugs sing. Interacting with Computers 14, 6: 793-819. https://doi.org/10.1016/S0953-5438(02)00026-7

[19] About | The Alliance for Access to Computing Careers. Retrieved April 21, 2016 from http://www.washington.edu/accesscomputing/about

[20] EdSharp. Retrieved November 8, 2017 from https://github.com/EmpowermentZone/EdSharp

[21] Learning Ally - Support for Dyslexia and Learning Disabilities. Retrieved May 7, 2016 from https://www.learningally.org

[22] Communities of Practice | AccessComputing. Retrieved December 1, 2018 from https://www.washington.edu/accesscomputing/getinvolved/educators-employers/communities-practice 